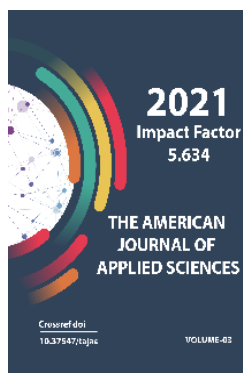

\title{
Research Of Prospective And Developed Influence Of Food Additives On Product Quality
}

\author{
Karimova Kamola Bahdirovna \\ Tashkent Polytechnic University Named After I. A. Karimova Assistant Of The Department Of \\ Biotechnology, Uzbekistan
}

\footnotetext{
Journal Website: http://theamericanjour nals.com/index.php/taj as

Copyright: Original content from this work may be used under the terms of the creative commons attributes 4.0 licence.
}

\section{ABSTRACT}

This work is devoted to the study of the influence of certain types of local green tea on the change in the physical and biological properties of non-alcoholic products.

\section{KEYWORDS}

Soft drinks, antioxidant activity, herbal ingredients, green tea, local raw materials, multicomponent teas; coulometric analysis method; healthy food products.

\section{INTRODUCTION}

Nutrition is one of the most important and reliable ways to improve health, regulate life, prevent and heal chronic degenerative diseases. Since ancient times, people have understood the great importance of nutrition for health. The thinkers of antiquity Hippocrates, Paracelsus, Galen and others devoted whole treatises to the medicinal properties of various types of drinks and its rational consumption. An outstanding scientist wrote a lot about this, for example, the scientist of the East Abu Ali Ibn Sina (Avicenna) considered healing drinks and food a source of health, strength, vigor. I.I. Mechnikov believed that people age prematurely and die due to improper nutrition and that a person who eats rationally can live 120-150 years.

The vital activity of the organism is provided by two processes - assimilation and dissimilation, which are based on the exchange of substances between the internal (cells of the body) and the external environment. Healing drinks and food, which enter the body with nutrients. These primarily 
include proteins, fats and carbohydrates, the oxidation of which releases a certain amount of heat.

As a rule, healthy food products are natural, high-quality products, the range of which is constantly expanding. For example, in the segment of tea products, various types of tea are presented in their composition: monobased, poly-component with the addition of fruits, berries, plant flowers that enhance the biological usefulness of such teas; herbal, fruit, tonic, flavored, healing, etc. Herbal teas are distinguished by biological, physiological, energetic, preventive and other useful properties.

Nutritional supplements and advances in food technology help make this possible. Today it is important for the consumer to enjoy both food and drinks. As a physical one: to enjoy every possible taste sensation, as well as to quench a little thirst and spiritual contemplation of color, texture and form. For centuries, nutritional supplements have found their purpose in a wide variety of foods.

Consumer demand and changes in the structure are conditioned by socio-economic factors, the desire to reduce to a minimum harmful drinks in catering establishments and at home. But the growth in demand is increasing for plant products with a reduced amount of chemical additives, sugar and a high content of dietary fiber, vitamins, minerals and other biologically active substances are the main prerequisites for the development of drinks and the search for new raw materials that meet the needs of the modern consumer.
Over the past ten years, interest in research on the active ingredients of green tea and their use in the treatment of many diseases has not faded. The use of green tea catechins and bioflavonoids in oncology, cardiology, endocrinology, gerontology, dermatology, cosmetology, hepatology and other fields of medicine is being studied. The results published so far show the effectiveness of green tea, its medicinal properties, many of which are still not fully understood. Let us discuss some of the studied mechanisms of action of green tea.

Herbal teas are distinguished by biological, physiological, energetic, preventive and other useful properties. Regularly branded teas based on green and black teas with added health-promoting biocomponents and presented in a dynamic premium sector.

The health-improving and preventive effect of the use of fortified foods is associated with the action of the irreplaceable substances contained in it, the effect of which on health has been proven.

The total volume of the Russian tea market over the past few years has been approximately 160 thousand tons per year. The average Russian annually consumes 1-1.25 $\mathrm{kg}$ of this product [1].

Today, black tea all over the world, as well as in Russia, surpasses all other types of this drink in terms of production. If earlier in our country there was a shortage of green tea, then in the new economy, the consumption of black tea decreased from 96 to $90 \%$, and green tea - increased from 4 to $8 \%$, herbal and herbal teas - up to $2 \%$. 
There is a general demand for high-quality, elite, exclusive varieties of tea. Tea enriched with various useful components is an independent food product, especially in demand in the convinient food format convenient and fast food that can be consumed "on the go" due to its beneficial properties and ergonomic packaging, which is of particular importance in a dynamic pace of human life in the metropolis. The development of this area is facilitated by innovative approaches that allow expanding the practical possibilities for the development of healthy and functional food products, characterized by the optimal content of substances physiologically valuable for the human body. Classic teas include black and green teas, and the former is the leader in both the production and use of this product. At the same time, the consumption of green tea is growing, which is considered the "elixir of longevity", as well as one of the best drinks for quenching thirst. As a result of certain stages of technological processing, such tea to the greatest extent retains useful natural properties in its composition.

Green tea is able to remove radionuclides from the body, has bactericidal properties, and exhibits a mild antidepressant effect. The data on the biochemical composition of tea indicate not only its high nutritional value, but also about the pharmacological properties due to a wide variety of physiologically active compounds. The total number of chemicals identified in tea is about 2,000, and their biochemical role has not yet been fully understood. Further research is needed in this direction.

Antioxidant effect is the most important property, which is provided by the presence in green tea of such active components as the polyphenols epigallocatechin-3-gallate (EGCG) and epigallocatechin (EGC), the flavonoid quercetin ( $\mathrm{Qu}$ ), vitamins $\mathrm{C}$ and $\mathrm{E}$. For example, in a study conducted by British urologists on prostate cancer cells, it was found that the addition of epigallocatechin-3-gallate 30 minutes before radiation therapy significantly reduces its effectiveness. The increase in the resistance of tumor cells is explained by the fact that epigallocatechin-3-gallate doubles the level of superoxide dismutase in them, thereby significantly suppressing free radical oxidation induced by radiation therapy [14]. In addition, epigallocatechins-3-gallate, epicatechin-3-gallate, quercetin, vitamins C and $\mathrm{E}$ actively bind free radicals, in particular superoxide radical and singlet oxygen, protecting the membranes and DNA of cells from damage [6].

The antioxidant and cytoprotective properties of green tea can be used in the combined treatment of almost any disease associated with oxidative stress. The fields of application of green tea can be the therapy of malignant neoplasms (during the course of chemotherapy or radiation therapy), the treatment of broncho-pulmonary and cardiovascular diseases and chronic intoxication, the protection of the skin from the damaging effects of ultraviolet radiation, etc.

The anticarcinogenic effect is one of the most studied properties of green tea. Numerous studies have proven the effectiveness of green tea catechins in the combined treatment of breast cancer, prostate cancer, cervical cancer, bladder tumors, and liver cancer. Epicatechin-3-gallate and epigallocatechin-3-gallate are currently 
recognized as the main antineoplastic agents in green tea. Their action is realized at several stages of carcinogenesis: they disrupt transduction - signal transmission inside the tumor cell, inhibiting the proliferation of tumor cells; activate apoptosis of tumor cells; reduce the expression of endothelial growth factor (VEGF) and block angiogenesis in tumor tissue. Thus, green tea catechins inhibit tumor growth, disrupt its nutrition and spread [12].

\section{Cardioprotective Effects - Singaporean} scientists investigated the protective effect of epigallocatechin-3-gallate in doxorubicininduced cardiomyocyte damage. The study was carried out in vitro, on a cardiomyocyte cell line. It was found that epigallocatechin-3gallate restores the calcium concentration in the sarcoplasmic reticulum of cardiomyocytes to physiological norms, and also binds reactive oxygen species, protecting cardiomyocytes from oxidative stress. Thus, this study showed that epigallocatechin-3-gallate can be used to protect heart cells from the damaging effects of doxorubicin, which is important for chemotherapy [16].

Antiviral effects of green tea Ciesek et al. [4] have shown that green tea catechins can be used to prevent hepatitis $C$ infection during organ transplantation. In a study on the line of human hepatocytes, it was shown that epigallocatechin-3-gallate prevents the introduction of the hepatitis $C$ virus into cells.

Thus, the use of green tea catechins may be part of an antiviral strategy aimed at preventing hepatitis $\mathrm{C}$ infection during organ transplantation [4].

Currently, the antiviral activity of epigallocatechin-3-gallate against HIV infection is being studied. In a study by Li et al. [10], epigallocatechin-3-gallate inhibited viral reverse transcriptase and prevented HIV replication prior to its integration into the host cell DNA. Thus, epigallocatechin-3-gallate can be used as a prophylactic agent in people at risk, as well as in combination therapy for HIV infection [10].

As a leader among herbal antioxidants, tea extract is used:

- As a powerful weapon against aging, helping to preserve youthfulness and beauty of the skin;

- To protect the skin from harmful substances and ultraviolet radiation;

- As a means of care for the skin of the face, especially mixed, sensitive, damaged, mature or "tired";

- For the care of dry and damaged hair;

- To strengthen and heal nails.

It has long been proven and undeniable that green tea has antioxidant, anti-inflammatory and photoprotective properties. Free radicals generated by ultraviolet radiation cause oxidative stress and photoinduced skin inflammation. They increase the secretion of matrix metalloproteinases, activate nuclear transcription factor kB (NFkB), which increases the synthesis of pro-inflammatory mediators (such as interleukins 1, 6 and 8, tumor necrosis factor) by skin cells. All this leads to damage to collagen and elastin fibers, destruction of hyaluronic acid and skin cell membranes [13].

Tannin is a mixture of tanning agents. From a chemical point of view, it is a heterogeneous substance, which includes a glucose ester containing an m-gallic acid radical. Another 
important constituent of tea is catechins natural substances belonging to the flavan group and representing polyoxy or polymethoxy derivatives. Catechins are widely distributed in the plant kingdom. A particularly large amount of catechins is found in tea plants, where it reaches $20-25 \%$. These are highly active substances from a biological point of view, in particular, they have a pronounced $P$ vitamin activity. Vitamin $P$, in addition to catechins, also contains leukoanthocyanins, flavonols and flavanones.

In the formation of the quality characteristics of tea, polyphenolic compounds play the main role [2]. They are a complex biochemical complex, which includes tannins, catechins, phenolic glycosides, phenol carboxylic acids, essential oils, as well as the products of enzymatic oxidation - theaflavins, thearubigins, etc. [3]. Tea contains caffeine (in black tea - up to $1.5-4.0 \%$ ) and various amino acids that characterize the quality of the product, especially green tea. These are alanine, asparagine, methionine, tyrosine, theanine, etc.

Tea contains cations and anions of alkali and alkaline earth metals and metal complexes of various nature. It is also rich in vitamins, including $C, E, K$, group $B$. But the main vitamin of tea is vitamin $P$, which strengthens the walls of the smallest vessels - capillaries, thereby preventing internal hemorrhages. In terms of the content of this component, tea has no equal in the plant world, and it is green tea that has the highest vitamin P activity. It is not for nothing that recently more and more attention has been paid to green tea, since from the point of view of biochemistry, this set of valuable components has a versatile and beneficial physiological effect on the human body. With all the simplicity of the technology for making green tea, up to a hundred different operations can be carried out in the manufacture of its elite varieties. Thanks to such methods of obtaining green tea, it is possible to preserve all the useful biologically active substances in it to the maximum. Another type of tea that is showing interest today is herbal teas. Rooibos is added to specially selected herbal teas. Rooibos is a shrub of Aspalantus Linearis native to South Africa and belongs to the legume family. Rooibos contains optimal sodium-potassium complex, vitamin $\mathrm{C}$, as well as macro and microelements such as iron, copper, fluorine, etc.

Rooibos teas are caffeine-free. This bush tea is the national drink in South Africa.

The purpose of this work is to determine the antioxidant activity of various types of consumed local tea in Uzbekistan. To obtain the necessary extracts, we used water and rectified alcohol. The main objects of the study were samples of local varieties of green tea. For the analyzes we needed local varieties like Samarkand-95 tea, Amir tea, and Imra green teas.

Today it is possible to compose a composition of herbal teas in three directions - Black Tea, Green Tea and Herbal Tea, which are original compositions created according to exclusive recipes using natural ingredients.

Determination of polyphenolic compounds in tea is one of the most objective indicators of its quality and serves as a criterion marker of its authenticity [8]. Typically, fake tea samples are low in natural antioxidants. 
This is especially evident in the falsification of elite types of tea. As the results of the study of antioxidant activity have shown, such multicomponent teas, enriched with fruits, berries and other natural ingredients, make it possible to create a number of food products that can be successfully used for a healthy lifestyle, since they are able to exhibit biocorrective, immunomodulating, tonic properties due to physiologically active a matrix that has a positive, healing effect on the human body.

Table 1 shows the values of the total antioxidant activity of aqueous and ethanol extracts of tea samples.

\begin{tabular}{|c|c|c|c|}
\hline \multirow{2}{*}{ № } & \multirow{2}{*}{ Samples of green teas } & The value of the total antioxidant activity \\
\cline { 2 - 4 } & Tea -« Samarkand -95» & 153281 & B \\
\hline 1 & Tea - «Amir» & 141178 & 84884 \\
\hline 2 & Tea - «Impra» & 121167 & 51083 \\
\hline 3 & &
\end{tabular}

The values of the total antioxidant activity of aqueous (A) and ethanol (B) tea samples, $\mathrm{mg}$ in terms of ascorbic acid $(n=3, P=0.95)$

As can be seen from the table, the values of antioxidant activity depend both on the nature of the analyzed sample and on the nature of the extractant. Comparative analyzes of the studied tea samples were higher in the case of aqueous extracts compared to alcoholic ones. It was revealed in the process of hydrolysis from plant objects it was possible to extract a larger amount of substances with antioxidant properties, or rather, a larger amount, in particular, bioflavonoids with hydrophilic properties for the obtained samples of tea concentrates, passed into an aqueous solution.

Ethanol extracts are characterized by a lower content of antioxidants, but they retain their quality unchanged for a longer time in

comparison with aqueous extracts, since they have antibacterial properties.

\section{REFERENCES}

1. Лобач, А. Всероссийский рынок чая/А. Лобач//Кофе и чай в России. - 2008. №6. - C. 30-32.

2. Запрометов, М.Н. Фенольные соединения: распространение, метаболизм и функции в растениях/М.Н. Запрометов. - М., 1993. - 272 с.

3. Татарченко, И.И. Химия субтропических и пищевкусовых продуктов/ И.И. 
Татарченко, И.Г. Мохначев, Г.И. Касьянов. - М.: Изд. центр «Академия», 2003. - 256 C.

4. Cheng T. O. All teas are not created equal: the Chinese green tea and cardiovascular health. Int J Cardiol 2006; 108:301-308.

5. Ciesek S., von Hahn T., Colpitts C. C. et al. The green tea polyphenol epigallocatechin-3-gallate (EGCG) inhibits hepatitis $\mathrm{C}$ virus (HCV) entry. Hepatology 2011; 11 августа. [Электронная публикация.]

6. Elmets C., Singh D., Tubesing K. et al. Cutaneous photoprotection from ultraviolet injury by green tea polyphenols. J Am Acad Dermatol 2001; 44:425-432.

7. He Y., Cui J., Lee J. C. et al. Prolonged exposure of cortical neurons to oligomeric amyloidimpairs NMDA receptor function via NADPH oxidase-mediated ROS production: protective effect of green tea Neuro 2011; 3:e00050.

8. Heinrich U., Moore C. E., De Spirt S. et al. Green tea polyphenols provide photoprotection, increase microcirculation, and modulate skin properties of women. J Nutr 2011; 141:1202-1208.

9. Hodgson J. M., Croft K. D. Tea flavonoids and cardiovascular health. Mol Aspects Med 2010;31:495-502.

10. Kim J., Hwang J. S., Cho Y. K. et al. Protective effects of epigallocatechin-3gallate on UVA and UVB induced skin damage. Skin Pharmaco-Appl Skin Physiol 2001; 14:11-19.

11. Li S., Hattori T., Kodama E. N. Epigallocatechin gallate inhibits the HIV reverse transcription step. Antivir Chem Chemother 2011; 21:239-243.
12. Mahmood T., Akhtar N., Khan B. A. et al. Outcomes of $3 \%$ green tea emulsion on skin sebum production in male volunteers. Basic Med Sci 2010; 10:260—264.

13. Pan M. H., Chiou Y. S., Wang Y. J. et al. Multistage carcinogenesis process as molecular targets in cancer chemoprevention by epicatechin-3-gallate. Food Funct 2011; 2:101-110.

14. Senftleben U., Karin M. The ILK/NF!Kappa B pathway. Crit Care Med 2002; 30:18-26

15. Thomas F., Holly J. M., Persad R. et al. Green tea extract (epigallocatechin-3gallate) reduces efficacy of radiotherapy on prostate cancer cells. Urology 2011; 78:475.e15-e21.

16. Vayalil P. K., Mittal A., Hara Y. et al. Green tea polyphenols prevent UV light induced oxidative damage and matrix metalloproteinases expression in mouse skin. J Invest Dermatol 2004;122:14801487.

17. Zheng J., Lee H. C., Bin Sattar M. M. et al. Cardioprotective effects of epigallocatechin-3-gallate against doxorubicin-induced cardiomyocyte injury. Eur J Pharmacol 2011;652:82-88. 